\title{
A framework for benchmarking of homogenisation algorithm performance on the global scale
}

\author{
K. Willett ${ }^{1}$, C. Williams ${ }^{2}$, I. T. Jolliffe ${ }^{3}$, R. Lund ${ }^{4}$, L. V. Alexander ${ }^{5}$, S. Brönnimann ${ }^{6}$, L. A. Vincent ${ }^{7}$, S. Easterbrook $^{8}$,

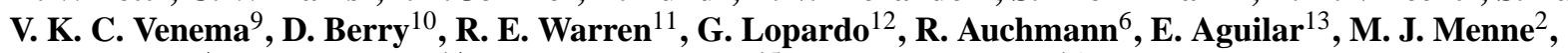 \\ C. Gallagher ${ }^{4}$, Z. Hausfather ${ }^{14}$, T. Thorarinsdottir ${ }^{15}$, and P. W. Thorne ${ }^{16}$ \\ ${ }^{1}$ Met Office Hadley Centre, FitzRoy Road, Exeter, UK \\ ${ }^{2}$ National Climatic Data Center, Ashville, NC, USA \\ ${ }^{3}$ Exeter Climate Systems, University of Exeter, Exeter, UK \\ ${ }^{4}$ Department of Mathematical Sciences, Clemson University, Clemson, SC, USA \\ ${ }^{5}$ ARC Centre of Excellence for Climate System Science and Climate Change Research Centre, \\ University of New South Wales, Sydney, Australia \\ ${ }^{6}$ Oeschger Center for Climate Change Research \& Institute of Geography, University of Bern, Bern, Switzerland \\ ${ }^{7}$ Climate Research Division, Science and Technology Branch, Environment Canada, Toronto, Canada \\ ${ }^{8}$ Department of Computer Science, University of Toronto, Toronto, Canada \\ ${ }^{9}$ Meteorologisches Institut, University of Bonn, Bonn, Germany \\ ${ }^{10}$ National Oceanography Centre, Southampton, UK \\ ${ }^{11}$ College of Engineering, Mathematics and Physical Sciences, University of Exeter, Exeter, UK \\ ${ }^{12}$ Istituto Nazionale di Ricerca Metrologica (INRiM), Torino, Italy \\ ${ }^{13}$ Centre for Climate Change, Universitat Rovira i Virgili, Tarragona, Spain \\ ${ }^{14}$ Berkeley Earth, Berkeley, CA, USA \\ ${ }^{15}$ Norwegian Computing Center, Oslo, Norway \\ ${ }^{16}$ Nansen Environmental and Remote Sensing Center, Bergen, Norway
}

Correspondence to: K. Willett (kate.willett@metoffice.gov.uk)

Received: 27 February 2014 - Published in Geosci. Instrum. Method. Data Syst. Discuss.: 4 June 2014 Revised: 21 August 2014 - Accepted: 30 August 2014 - Published: 25 September 2014

\begin{abstract}
The International Surface Temperature Initiative (ISTI) is striving towards substantively improving our ability to robustly understand historical land surface air temperature change at all scales. A key recently completed first step has been collating all available records into a comprehensive open access, traceable and version-controlled databank. The crucial next step is to maximise the value of the collated data through a robust international framework of benchmarking and assessment for product intercomparison and uncertainty estimation. We focus on uncertainties arising from the presence of inhomogeneities in monthly mean land surface temperature data and the varied methodological choices made by various groups in building homogeneous temperature products. The central facet of the benchmarking process is the creation of global-scale synthetic analogues to the real-world
\end{abstract}

database where both the "true" series and inhomogeneities are known (a luxury the real-world data do not afford us). Hence, algorithmic strengths and weaknesses can be meaningfully quantified and conditional inferences made about the real-world climate system. Here we discuss the necessary framework for developing an international homogenisation benchmarking system on the global scale for monthly mean temperatures. The value of this framework is critically dependent upon the number of groups taking part and so we strongly advocate involvement in the benchmarking exercise from as many data analyst groups as possible to make the best use of this substantial effort. 


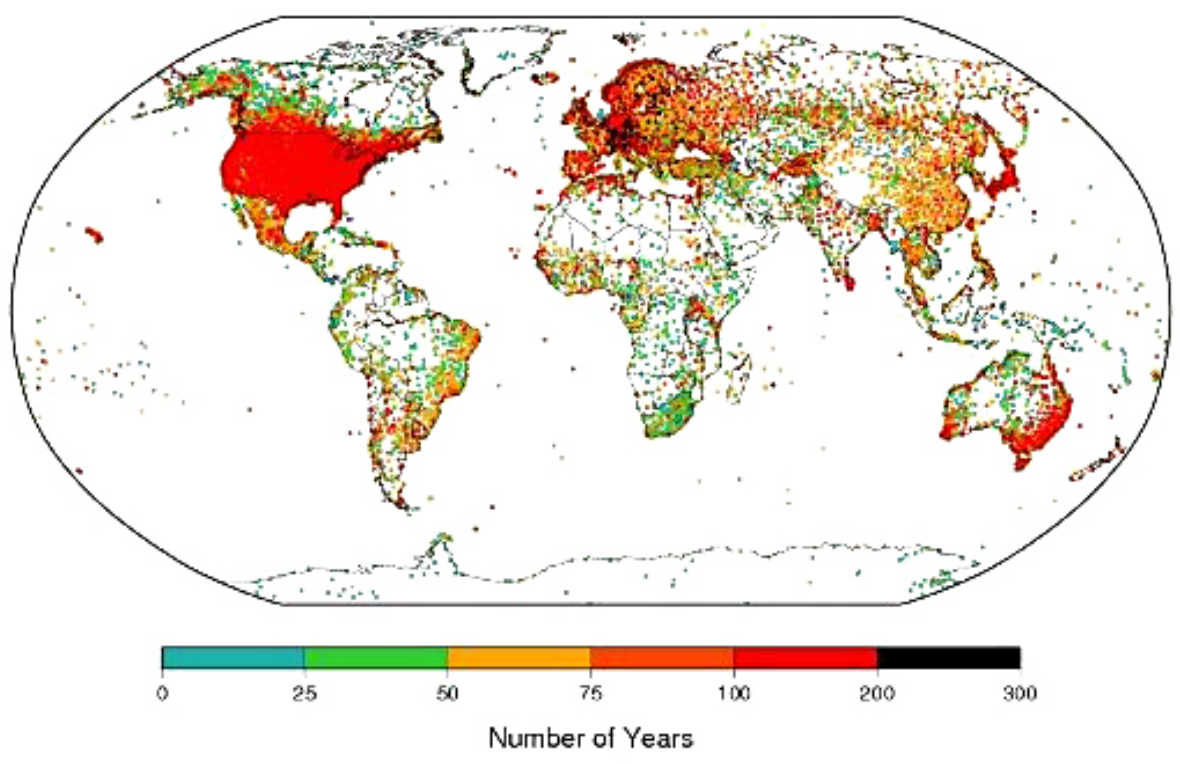

Figure 1. Station locations coloured by length of record for version1 of the ISTI Land Meteorological Databank stage 3 (recommended merged version) version 1.0.0 (source: Fig. 8 in Rennie et al., 2014).

\section{Introduction}

Monitoring and understanding our changing climate requires freely available data with good spatial and temporal coverage that is of high quality, with the remaining uncertainties well quantified. The International Surface Temperature Initiative (ISTI; www.surfacetemperatures.org; Thorne et al., 2011) is striving towards substantively improving our ability to robustly understand historical land surface air temperature change at all scales. A key recently completed first step has been collating all known freely available land surface meteorological records into an open access, traceable to known origin where possible, and version controlled databank (Rennie et al., 2014). To date the focus has been on monthly temperature time series, so far achieving a database of just over 32000 unique records in the first release version as it stood on 20 June 2014 (Fig. 1).

There are multiple additional processes that must be performed to transform these fundamental data holdings into high-quality-data products that are suitable for robust climate research, henceforth referred to as climate data records (CDRs). These processes include: quality control, homogenisation, averaging, and in some cases interpolation. At present, a number of independent climate data groups maintain CDRs of land surface air temperature. These can range from data sets at global, regional or national/local scales of single stations or gridded products. Each uses its own choice of methods to process data from the raw observations to a CDR. In most cases, these methods are automated, given the large number of stations, and purely statistical due to poor metadata availability.
ISTI's second programmatic focus is to set up a framework to evaluate these methodological choices that ultimately lead to structural uncertainties in the trends and variability from CDRs. In particular, the ISTI focuses on homogenisation algorithm skill. This can be tested using a set of synthetic temperature records, analogous to real station networks but where inhomogeneities have deliberately been added. As such, the "truth" about where and what errors exist is known a priori. The ability of the algorithm to locate the change points and adjust for the inhomogeneity, ideally returning the "truth", can then be measured. This community-based validation on a realistic problem is referred to as benchmarking henceforth.

Ideally, CDRs should represent points in space, and be free from any non-climatic influences thereby providing a clean, homogeneous record. The unknown degree to which they do not represent true climatic changes hampers robust understanding. This has consequences for informed decision making since observational records underpin all aspects of our understanding of climate change. With a handful of exceptions, historical measurements have not been made in an SI (International System of units) traceable manner. This means that instruments were not generally situated nor calibrated routinely to known international metrological standards. Even if they were, any calibration adjustment documentation is either unavailable or not easily accessible. Even the present day standard of a screened thermometer may still contain biases compared to the "true" WMO recommended standard of shaded free air temperature (WMO, 1992, 1998; Harrison, 2011, 2010). However, for analysis of changes in climate, achieving this WMO standard is less important than the long-term continuity of a given station and its practices. 
Unfortunately, change has been ubiquitous for the majority of station records (e.g. Lawrimore et al., 2011; Rohde et al., 2013). The dates of these changes (known as change points) are in many (very likely most) cases unknown and their impacts (known as inhomogeneities) either poorly quantified or more often than not entirely unquantified at source, necessitating subsequent analysis for change points and resulting inhomogeneities by third party analysts.

Climate observations made at individual stations exhibit multi-timescale variability made up of annual to decadal variations, seasonality and weather, all modulated by the station's microclimate. Inhomogeneities can arise for a number of reasons such as station moves, instrument changes and changes in their exposure (shelter change), changes to the surrounding environment and changes to observing/reporting practices. While in the simplest cases a station may have one abrupt inhomogeneity in the middle of its series, which is relatively easy to detect, the situation can be far more complex with multiple change points caused by a number of diverse inhomogeneities. For example, inhomogeneities may be:

- geographically or temporally clustered due to events which affect entire networks or regions (e.g. change in observation time)

- close to end points of time series

- gradual or sudden

- variance-altering

- combined with the presence of a long-term background trend

- small

- frequent

- seasonally or diurnally varying

and often a combination of the above. A good overview of inhomogeneities in temperature and their causes can be found in Trewin (2010). Identifying the correct date (change point) and magnitude for any inhomogeneity against background noise is difficult, especially if it varies seasonally. Even after detection a series of decisions are required as to whether and how to adjust the data. While decisions are as evidence-based as possible, some are unavoidably ambiguous and can have a further non-negligible impact upon the resulting data. This is especially problematic for large data sets where the whole process by necessity is automated.

In this context attaining station homogeneity is very difficult; many algorithms exist with varying strengths, weaknesses and levels of skill (detailed reviews are presented in Venema et al., 2012, Aguilar et al., 2003, and Peterson et al., 1998). Many are already employed to build global and regional temperature products (CDRs) routinely used in climate research (e.g. Xu et al., 2013; Trewin, 2013; Vincent et al., 2012; Menne et al., 2009). While these algorithms can improve the homogeneity of the data, both spatially and temporally, some degree of uncertainty is extremely likely to remain (Venema et al.,2012) depending on methodological choices. Narrowing these bands of uncertainty is highly unlikely to change the story of increasing global average temperature since the late 19th century. However, large-scale biases could be reduced (Williams Jr. et al., 2012) and estimates of temperature trends at regional and local scales, while becoming spatially more consistent, could be greatly affected.

The only way to categorically measure the skill of a homogenisation algorithm for realistic conditions is to test it against a benchmark. Test data sets for previous benchmarking efforts have included one or more of the following: as homogeneous as possible real data, synthetic data with added inhomogeneities, or real data with known inhomogeneities. Although valuable, station test cases are often relatively few in number (e.g. Easterling and Peterson, 1995) or lacking real-world complexity of both climate variability and inhomogeneity characteristics (e.g. Vincent, 1998; Ducré-Robitaille et al., 2003; Reeves et al., 2007; Wang et al., 2007; Wang, 2008a, b). A relatively comprehensive but regionally limited study is that of Begert et al. (2008), who used the manually homogenised Swiss network as a test case.

The European homogenisation community (the HOME project; www.homogenisation.org; Venema et al., 2012) is the most comprehensive benchmarking exercise to date. HOME used stochastic simulation to generate realistic networks of $\sim 100$ European temperature and precipitation records. Their probability distribution, cross- and autocorrelations were reproduced using a "surrogate data approach" (Venema et al., 2006). Inhomogeneities were added such that all stations contained multiple change points and the magnitudes of the inhomogeneities were drawn from a normal distribution. Thus, small undetectable inhomogeneities were also present, which influenced the detection and adjustment of larger inhomogeneities. Those methods that addressed the presence of multiple change points within a series (e.g. Caussinus and Lyazrhi, 1997, Lu et al., 2010; Hannart and Naveau, 2012; Lindau and Venema, 2013) and the presence of change points within the reference series used in relative homogenisation (e.g. Caussinus and Mestre, 2004; Menne and Williams, 2005, 2009; Domonkos et al., 2011) clearly performed best in the HOME benchmark.

Recent studies have generated synthetic data test cases with varying degrees of real-world characteristics (e.g. variance, station autocorrelation, multiple change points within a station record and a variety of inhomogeneity types) on larger scales (e.g. Menne and Williams, 2005; DeGaetano, 2006; Titchner et al., 2009; Williams et al., 2012). However, none offer sufficient complexity of test data with sufficient comprehensiveness of inhomogeneities. Furthermore, none are part of an internationally recognised system that could provide universally useful results. 
The ISTI benchmarks should lead to significant advancement over what is currently available. They will be global in scale, offer a better representation of real-world complexity both in terms of station characteristics and inhomogeneity characteristics and provide a repeatable internationally agreed assessment system. The requirement for homogenisation benchmarks is becoming increasingly important, because policy decisions of enormous societal and economic importance are now being based on conclusions drawn from observational data. In addition to underpinning our level of confidence in the observations, developing and engendering a comprehensive and internationally recognised benchmark system would provide three key scientific benefits:

1. objective intercomparison of data-products

2. quantification of the potential structural uncertainty of any one product

3. a valuable tool for advancing algorithm development.

The Benchmarking and Assessment Working Group was set up during the Exeter, UK, 2010 workshop for the ISTI to develop and oversee the benchmarking process for homogenisation of temperature products. Further details can be found at www.surfacetemperatures.org/ benchmarking-and-assessment-working-group and blog discussions can be found at http://surftempbenchmarking. blogspot.com. The Benchmarking and Assessment Working Group reports to the Steering Committee and is guided by the Benchmarking and Assessment Terms of Reference hosted at www.surfacetemperatures.org/ benchmarking-and-assessment-working-group.

The objective of this paper is to lay out the basic framework for developing the first comprehensive benchmarking system for homogenisation of monthly land surface air temperature records on the global scale. By defining what we believe a global homogenisation benchmarking system should look like, this paper is intended to serve multiple aims. Firstly, it provides an opportunity for the global community to provide critical feedback. Secondly, the document serves as a reference for our own purposes and others wishing to develop benchmarking systems for other parameters of problems of a similar nature. Finally, it constitutes a basis for further improvement down the line as knowledge improves. Future papers will provide detailed methodologies for the various components of the benchmarking system described herein.

Here, the focus is solely on monthly mean temperatures. These concepts broadly apply to daily or subdaily scales and additional variables (e.g. maximum temperature, minimum temperature, diurnal temperature range). However, both development of synthetic data and implementation of realistic inhomogeneities, while maintaining physical consistency across different variables simultaneously, requires significantly increased levels of complexity.

Geosci. Instrum. Method. Data Syst., 3, 187-200, 2014
The creation of spatio-temporally realistic analogue station data is discussed in Sect. 2. The development of realistic, but optimally assessable error models is discussed in Sect. 3. An assessment system that meets both the needs of algorithm developers and data-product users is explored in Sect. 4. A proposed benchmarking cycle to serve the needs of science and policy is described in Sect. 5. Section 6 contains concluding remarks.

\section{Reproducing "real-world" data - the analogue-clean worlds}

Simple synthetic analogue-station data with simple inhomogeneities applied may artificially award a high performance to algorithms that cannot cope with real-world data. A true test of algorithm skill requires global reconstruction of real-world characteristics including space and time sampling of the observational network. Hence, the ISTI benchmarks should replicate the spatio-temporal structure of the $\sim 32000$ stations in the ISTI databank stage 3 as far as possible (http://www.surfacetemperatures.org/databank; Rennie et al., 2014) available from ftp://ftp.ncdc.noaa.gov/pub/data/ globaldatabank/monthly/stage3/.

The benchmark data must have realistic trends, variability, station autocorrelation and spatial cross-correlation. Conceptually, we consider individual station temporal variability of ambient temperature $x$ at site $s$ and time $t$ as being able to be decomposed as

$x_{t, \mathrm{~s}}=c_{t, \mathrm{~s}}+l_{t, \mathrm{~s}}+v_{t, \mathrm{~s}}+m_{t, \mathrm{~s}}$,

where:

- $c$ represents the unique station climatology (the deterministic seasonal cycle). This will vary even locally due to the effects of topography, land surface type and any seasonal cycle of vegetation.

- $l$ represents any long-term trend (not necessarily linear, with possible seasonally varying components) that is experienced by the site due to climatic fluctuations such as in response to external forcings of the global climate system.

- $v$ represents region-wide climate variability at a range of scales (space and time). That is to say interannual and interdecadal variability due to El Niño and La Niña events, annular modes (AO and AAO), or multidecadal variations such as the Pacific Decadal Oscillation or Atlantic Multidecadal Oscillation. Such modes have regionally distinct patterns of surface temperature response; e.g. a positive AO (Arctic Oscillation) yields warm winters over northern Europe. 
- $m$ represents the station microclimate (local variability). Such station-specific deviations are oftentimes weakly autocorrelated and cross-correlated with nearby stations, but tend to be more distinct on a station-by-station basis than the remaining terms in Eq. (1).

These terms are assumed to be additive in this conceptual framework. This equation should not be considered to be a formal mathematical representation. All four components are deemed necessary to be able to subsequently build realistic series of $x_{t, \mathrm{~s}}$ on a network-wide basis that retain plausible station series, neighbour series and regional series. Below, a discursive description of the necessary steps and building blocks envisaged is given. A variety of methodological choices could be made when building the analogue-clean worlds. It is envisaged that the sophistication of methods will develop over time, improving the real-world representativeness of the benchmarks periodically.

Station-neighbour cross-correlations depend on more than distance, such as differences in elevation, aspect, continentality and land use. If real-world data are used to formulate all or part of a model to synthetically recreate station data, we need to be sure that errors within the real data (random or systematic) are not characterised and reproduced by the model. Ultimately, while analogue-clean world monthto-month station temperatures need not be identical to real station temperatures, realistic station climatology, variability, trends, autocorrelation and cross-correlation with neighbours should be maintained. Analogue-clean-world station temporal sampling can be degraded to varying levels of missing data as necessary.

Most algorithms analyse the difference between a candidate station and a reference station (or composite). Crucially, temperature climate anomalies (where the seasonal cycle, $c$, has been removed) are used to create the difference series. The large-scale trend, $l$, and variability, $v$, are highly correlated between candidate and reference series and so mostly removed by the differencing process. It is thus critical that the variability, autocorrelation and spatial cross-correlations in $m$ are realistic, and hence the variability and autocorrelation in station-reference difference series are realistic.

For the benchmarking process, global climate models (GCMs) can provide gridded values of $l$ (and possibly $v$ ) for monthly mean temperature. GCMs simulate the global climate using mathematical equations representing the basic laws of physics. GCMs can therefore represent plausible estimates of the short- and longer-term behaviour of the climate system resulting from solar variations, volcanic eruptions and anthropogenic changes (external forcings). They can also potentially represent natural large-scale climate modes (e.g. El Niño-Southern Oscillation - ENSO) and associated teleconnections (internal variability). However, the gridded nature of GCM output means that GCMs cannot give a sufficiently realistic representation of fine-scale meteorological data at point (station) scales. Hence, they cannot be used di- rectly to provide the $m$ and $c$ components at the point (station) level. The $l$ and $v$ components are expected to vary very little between stations that are close (e.g. within a grid box) and can reasonably be obtained by simple interpolation of GCM grid box values to point location.

There are three advantages of using GCMs to provide $l$ and $v$. Firstly, they provide globally consistent variability that can be associated with ENSO-type events or other real modes of variability with large spatial influence along with at least broad-scale topography (elevation, aspect, proximity to the coast, etc.) and its influence. Secondly, time series from a GCM will be free from inhomogeneity. Thirdly, there are different forcing scenarios available (e.g. no anthropogenic emissions, very high anthropogenic emissions) providing opportunities to explore how different levels of background climate change affect the homogenisation algorithm skill. Note that background trends may be seasonally variant, further complicating seasonally varying inhomogeneity detection. Such characteristics may be obtainable from a GCM.

The annually constant $c$ component in Eq. (1) is straightforward to calculate for each real station and then apply to the synthetic stations. The $m$ and $v$ (if not obtained from a GCM) component can be modelled statistically from the behaviour of the real station data, taking care to account for station inhomogeneity and not include it in the statistical model. Statistical methods such as vector-autoregressive (VAR)-type models (e.g. Brockwell and Davis, 2006) can reproduce the spatio-temporal correlations but limitations exist where station records are insufficiently long or stable enough to be modelled. Balancing sophistication of methods with automation and capacity to run on $~ 32000$ stations is key. Ensuring spatial consistency across large distances (hundreds of kilometres) necessitates high-dimensional-matrix computations or robust overlapping window techniques.

The key measures of whether benchmark clean worlds are good enough are as follows:

- station to neighbour cross-correlation

- standard deviation and autocorrelation of station minus neighbour difference series (of climate anomalies)

- station autocorrelation.

These measures should be compared between real networks that we know to be of high quality (relatively free from random and systematic error) such as NOAA's USCRN (United States Climate Reference Network; http://www.ncdc.noaa. gov/crn/) and the collocated analogue-clean world stations.

\section{Devising realistic but optimally assessable error models - the analogue-error worlds}

The analogue-error worlds should be created by adding the chosen types of inhomogeneities to analogue-clean worlds. 
Ideally each analogue-error world would be based on a different analogue-clean world to prevent prior knowledge of the "truth" (analogue-clean world). These error models should be designed with the three aims of the ISTI in mind, i.e. to aid product intercomparison, to help quantify structural uncertainty, and to aid methodological advancement. There should be blind benchmarks, where the answers/analogueclean worlds underlying the released analogue-error worlds will not be made public for a time. Additionally, there should be some open benchmarks, where the answers/analogueclean worlds will be publicly available immediately.

Blind benchmarks should be used for formal assessment of algorithms and data products. By being blind they prevent optimisation to specific features. While certain features will be widely known, it should not be known which world explores which type of features or the exact change point/inhomogeneity magnitude. For the most part these blind worlds should be physically plausible scenarios based on our understanding of real-world issues. The inclusion of a control case of a homogeneous world will enable assessing the effect of false detections and the potential for algorithms to do more harm than good. Ultimately, they should be designed to lead to clear and useful results, distinguishing strengths and weaknesses of algorithms against specific inhomogeneity and climate data characteristics. They need to achieve this without completely overloading algorithm creators from the outset, either with a multitude of complexities in all cases or with too many analogue-error worlds to contend with.

The open benchmarks will enable algorithm developers to conduct their own immediate tests comparing their homogenised efforts from the analogue-error worlds with the corresponding analogue-clean worlds. These open worlds will also be useful for exploring some of the more exotic problems or alternatively those straightforward issues that do not require a full global station database to explore.

Systematic errors are the key problem for station homogeneity and the prime focus for these benchmarks. These are persistent offsets or long-term trends away from the true ambient temperature (metrologically speaking, an artefact that causes the measurement to differ in a sustained manner from the true value of the measurand). Random errors are also prevalent in many observational records. These arise from isolated instrument faults or observer/transmission and collation mistakes. For monthly averages, random errors at observation times will often average out. Given a reasonable level of quality control, an essential step in any CDR processing, these errors are not thought to impact long-term-trend assessment although for individual stations this may not be the case.

To ensure focus on homogenisation methods, at least the first benchmark cycle should include only systematic errors and not random errors. Hence, users will not be required to quality control the analogue-error worlds although they are strongly recommended to quality control the real ISTI data- bank. We note that in some cases a change point may be preceded by a systematic increase in random error - for example, an instrument or shelter could deteriorate gradually until a point at which it is replaced. In future versions of the benchmarks, specific error worlds could include known types of random errors to test how this affects the homogenisation algorithm skill.

Themes of different systematic inhomogeneities can be added to the analogue-clean world stations to create inhomogeneous analogue-error worlds. Conceptually, for any analogue-station $x$ as denoted by Eq. (1) a $d$ term can be added to represent an inhomogeneity at time $t$ and site $s$ to give an observed value $x^{\prime}$ which differs from the true value $(x)$ :

$x_{t, \mathrm{~s}}^{\prime}=c_{t, \mathrm{~s}}+l_{t, \mathrm{~s}}+v_{t, \mathrm{~s}}+m_{t, \mathrm{~s}}+d_{t, \mathrm{~s}}$.

At any point in time, $d$ may be zero, a constant (possibly with some seasonal or climate-related variation; e.g. an instrument change may yield a warm bias in winter and a cool bias in summer if not well ventilated) or a value that grows/declines over time as e.g. a tree grows or urban areas encroach. A growing $d$ term may be smooth or jumpy. Experience with current benchmarks over restricted regions (Williams et al., 2012; Venema et al., 2012) suggests that several artefacts exist in most station records such that the $d_{t, \mathrm{~s}}$ term may change several times during the period of record of a station (roughly every 10-30 years or more often).

In a perfect case, a homogenisation algorithm would detect $d$ in the analogue-error world correctly, remove it, and adjust $x^{\prime}$ to its true ambient temperature $x$ from the original analogue-clean world (Eq. 1). By necessity, homogenisation algorithms have to make an assumption that a given station is at least locally representative at some point in its record. For convenience, and because the major interest is change in temperature rather than actual temperature, the most recently observed period is treated as the reference period by the majority of algorithms. Any adjustments are made relative to this period. This creates issues for a user interested in the actual temperature because for any one station the period of highest absolute accuracy may not be the most recent period. However, it is not really possible to detect which period is the most accurate for each station and having multiple reference periods in the benchmarks would make assessment far more complex and less useful. Hence, our assessment will assume all stations are representative in the most recent part of their record such that $d$ is zero at present day and additive backwards.

These $d$ elements should be physically plausible representations of known causes of inhomogeneity (e.g. station moves, instrument malfunctions or changes, screen/shield changes, changes to observing practice over time, and local environment changes) as summarised in Table 1. A range of frequencies and magnitudes should be explored. Ideally, the effect on temperature, and hence $d$, from the change in weather (e.g. radiation, wind speed, rainfall and humidity) 
Table 1. Known inhomogeneities between observed air temperature and the ambient air temperature representative of a given location in terms of problems, possible causes and effects, physical solutions, and possible implementations in modelling a benchmark.

\begin{tabular}{|c|c|c|c|c|}
\hline Problem & Possible cause & Possible effect & Physical solution & Benchmark modelling \\
\hline $\begin{array}{l}\text { Reported air } \\
\text { temperature is } \\
\text { not measured } \\
\text { air temperature }\end{array}$ & $\begin{array}{l}\text { Errors in reporting, } \\
\text { units, data } \\
\text { transmission, } \\
\text { etc. }\end{array}$ & $\begin{array}{l}\text { Abrupt change } \\
\text { that is either } \\
\text { constant over } \\
\text { time or a function } \\
\text { of temperature }\end{array}$ & $\begin{array}{l}\text { Identify error and correct } \\
\text { (difficult to adjust } \\
\text { using an automated } \\
\text { process because errors } \\
\text { may be unique) }\end{array}$ & $\begin{array}{l}\text { Draw from past experience. } \\
\text { Apply blanket changes using } \\
\text { a constant or simple formula } \\
\text { as a function of } \\
\text { temperature alone }\end{array}$ \\
\hline $\begin{array}{l}\text { Measured air } \\
\text { temperature is } \\
\text { not true air } \\
\text { temperature }\end{array}$ & $\begin{array}{l}\text { Instrument error } \\
\text { (malfunction or } \\
\text { change intype), } \\
\text { calibration error }\end{array}$ & $\begin{array}{l}\text { Abrupt (or gradual } \\
\text { for some instrument } \\
\text { malfunctions) change } \\
\text { that is either constant or } \\
\text { a function of temperature } \\
\text { (or drifting for some } \\
\text { instrument malfunctions) } \\
\text { (random errors should be } \\
\text { removed by quality-control } \\
\text { process) }\end{array}$ & $\begin{array}{l}\text { Identify error and correct, } \\
\text { using metadata where } \\
\text { available }\end{array}$ & $\begin{array}{l}\text { Statistically model distributions } \\
\text { of typical size and frequency. } \\
\text { Apply blanket changes using } \\
\text { a constant or simple formula } \\
\text { as a function of } \\
\text { temperature alone }\end{array}$ \\
\hline $\begin{array}{l}\text { True air } \\
\text { temperature } \\
\text { is not } \\
\text { representative } \\
\text { ambient air } \\
\text { temperature }\end{array}$ & $\begin{array}{l}\text { Change in } \\
\text { instrument } \\
\text { shield, practice } \\
\text { or microclimate } \\
\text { (due to move } \\
\text { of instrument) }\end{array}$ & $\begin{array}{l}\text { Abrupt change } \\
\text { that is likely to } \\
\text { vary as a function } \\
\text { of variables such } \\
\text { as radiation, } \\
\text { wind speed and } \\
\text { soil moisture }\end{array}$ & $\begin{array}{l}\text { Identify error and correct. } \\
\text { Modelling energy } \\
\text { balance of shield } \\
\text { and microclimatic } \\
\text { conditions }\end{array}$ & $\begin{array}{l}\text { Statistically model } \\
\text { distributions of typical } \\
\text { size and frequency. } \\
\text { Semi-empirical modelling } \\
\text { of errors based on } \\
\text { assumed changes in } \\
\text { radiation, wind speed } \\
\text { and soil moisture }\end{array}$ \\
\hline $\begin{array}{l}\text { Representative } \\
\text { ambient air } \\
\text { temperature is } \\
\text { affected by } \\
\text { local influences }\end{array}$ & $\begin{array}{l}\text { Changes in } \\
\text { station } \\
\text { surroundings, } \\
\text { urbanisation }\end{array}$ & $\begin{array}{l}\text { Gradual or abrupt } \\
\text { change that is likely } \\
\text { to vary as a function of } \\
\text { variables such as } \\
\text { radiation, wind speed } \\
\text { and soil moisture }\end{array}$ & $\begin{array}{l}\text { Correction not desirable } \\
\text { from a physical or } \\
\text { monitoring perspective, } \\
\text { but from a detection } \\
\text { and attribution perspective. } \\
\text { Modelling energy balance } \\
\text { of shield and } \\
\text { microclimatic conditions }\end{array}$ & $\begin{array}{l}\text { Statistically model } \\
\text { distributions of typical } \\
\text { size and frequency. } \\
\text { Semi-empirical and } \\
\text { possibly numerical } \\
\text { modelling of resulting } \\
\text { trend and its high-frequency } \\
\text { characteristics due to changes } \\
\text { in radiation, wind speed and } \\
\text { soil moisture }\end{array}$ \\
\hline $\begin{array}{l}\text { Different } \\
\text { ambient air } \\
\text { temperatures } \\
\text { are merged }\end{array}$ & $\begin{array}{l}\text { Change in } \\
\text { station } \\
\text { location }\end{array}$ & $\begin{array}{l}\text { Abrupt change } \\
\text { that is likely to } \\
\text { vary as a function } \\
\text { of variables such } \\
\text { as radiation, } \\
\text { wind speed and } \\
\text { soil moisture }\end{array}$ & $\begin{array}{l}\text { Unmerge (correction not } \\
\text { desirable from a physical } \\
\text { perspective, especially for } \\
\text { high-frequency data) or } \\
\text { correct (low-frequency } \\
\text { large-scale monitoring and } \\
\text { detection and attribution } \\
\text { perspective) }\end{array}$ & $\begin{array}{l}\text { Change in spatial sampling } \\
\text { from the analogue-known } \\
\text { world to merge series }\end{array}$ \\
\hline $\begin{array}{l}\text { Changes in } \\
\text { diurnal } \\
\text { sampling } \\
\text { affect } \\
\text { statistics }\end{array}$ & $\begin{array}{l}\text { Change in } \\
\text { observation } \\
\text { time }\end{array}$ & $\begin{array}{l}\text { Abrupt change } \\
\text { that is likely to } \\
\text { vary as a function } \\
\text { of variables such } \\
\text { as radiation }\end{array}$ & $\begin{array}{l}\text { Split (correction } \\
\text { not desirable } \\
\text { from a physical } \\
\text { perspective) or } \\
\text { correct (low-frequency } \\
\text { large-scale monitoring } \\
\text { and detection and } \\
\text { attribution perspective) }\end{array}$ & $\begin{array}{l}\text { Statistically model distributions } \\
\text { of typical size and frequency. } \\
\text { Change in temporal sampling } \\
\text { from synthetic source data } \\
\text { or in the case of low-frequency } \\
\text { GCM output use } \\
\text { semi-empirical modelling } \\
\text { of errors based on } \\
\text { assumed changes in radiation }\end{array}$ \\
\hline
\end{tabular}


should be taken into account if possible. Given the current state of knowledge this will in many respects be an assumption based on expert judgement. Many complicated examples of covariate impacts on $d$ exist. For example, in soil-moisture-limited regions changing vegetation between wet years and dry years increases variability compared to a more constant soil-moisture environment (B. Trewin, personal communication, 2013; Seneviratne et al., 2012).

Inhomogeneities added should be both abrupt and gradual, including the effects of land use change, such as ruralto-urban developments, which are important for some applications. They should explore changes that vary with season, which can result in changes in variance as well as the mean. Some should be geographically common, reflecting both region-wide changes, and others isolated. Isolated changes may arise due to the need to replace broken equipment or when stations are maintained by individual volunteers or groups. Region-wide changes tend to occur in networks that are centrally managed or owned.

Some inhomogeneities are reasonably well understood and apply to a given period and region, e.g.:

- change from north wall measurements to Stevenson screens in the 19th century in Austria (Böhm et al., 2001)

- change from open stands (French, Montsouris, Glaisher) to Stevenson screens around the early 1900s in Spain (Brunet et al., 2006)

- change from Wild screens to Stevenson screens in the mid-20th century in Switzerland (Auchmann and Brönnimann, 2012) and in central and eastern Europe (Parker, 1994)

- change from Stevenson screens with liquid in glass thermometers to electronic thermistors (maximum/minimum temperature system) in the USA in the mid-1980s (Quayle et al., 1991; Menne et al., 2009)

- change from tropical thatched sheds to Stevenson screens in the tropics during the early 20th century (Parker, 1994)

- time of observation change from afternoon (sunset) to morning in USA stations over the 20th century (Karl et al., 1986).

These (or similar) could be included in one or more of the analogue-error worlds. However, more commonly, inhomogeneities are undocumented and unknown and could be of any magnitude, frequency, clustering or sign and are likely a combination of all these. Current efforts are ongoing to collect together times and types of changes known to have occurred for each country (http://www.surfacetemperatures. org/benchmarking-and-assessment-working-group\#
Working\%20Group\%20Documents). It is envisaged to replicate what we believe to be realistic regional distributions of inhomogeneities within at least some subset of the analogue-error worlds.

Metadata have been used to improve the detection of change points. Substantive metadata are digitally available for the US Cooperative Observer Network which comprises the bulk of US station data. Elsewhere, digital holdings are rare but will likely be made available in the future. In terms of improving homogenisation, the need to digitise metadata is arguably as critical as the need for digitising more station records. Therefore, alongside the analogue-error worlds some change points should be documented, some should not be and some should have documented changes where no actual temperature change is effected. The latter could relate either to an inconsequential change in instrumentation/procedure/location or a false metadata event in the record.

A selection of error models should be chosen to explore different features of both the type of inhomogeneity (e.g. size, frequency, seasonality, and geographic pervasiveness) and characteristics of the real-world observing systems (e.g. variability, trends, missing data, station sparsity, and availability of metadata). Worlds should incorporate a mix of the inhomogeneity types discussed above and the set of worlds should be broad, covering a realistic range of possibilities so as not to unduly penalise or support any one type of algorithm or too narrowly confine us to one a priori hypothesis as to real-world error structures. They should methodically address key questions by testing skill under these situations (e.g. change-point clustering versus sparsity, proximity of change points to the end versus the middle of station records, large versus small inhomogeneities, a combination of both, and the presence of strong versus no background trend).

Periodic versions of the benchmarks should explore different issues but also improve the error worlds where necessary. Evaluation of the benchmarks themselves is discussed as level 4 assessment in Sect. 4.

\section{Developing an assessment system that meets all needs}

Any data-product creators utilising the ISTI databank and undertaking homogenisation will be encouraged to take part in the benchmarking as a means of improving the uncertainty estimation (specifically homogenisation uncertainty) of their product. This will involve running their homogenisation algorithms on the blind analogue-error worlds to create adjusted analogue-error worlds, just as they have done for the real ISTI databank stations. To take part they must submit homogenised benchmark data and results to the Benchmarking and Assessment Working Group for assessment. In time this process could be automated through a web page which would also assist users of the open benchmarks. 
There are two components of assessment: how well are individual change points located and their inhomogeneity characterised; and how similar is the adjusted analogue-error world to its corresponding analogue-clean world? An algorithm may do very well at retrieving the climatology or trend behaviour without necessarily performing well in detecting individual change points/inhomogeneities, or vice versa. Algorithms may perform well at characterising long-term regional trends but have markedly different performance characteristics at subregional and interannual to multidecadal timescales.

The assessment can be split into four different levels:

- Level 1 - difference between analogue-clean world and homogenised series analogue-error world climatology, variance and trends.

- Level 2 - measures such as hit and false alarm rates for correct detection of change points and inhomogeneity character.

- Level 3 - detailed assessment of strengths and weaknesses against specific types of inhomogeneity and observing system issues.

- Level 4 - reality of the various analogue-error worlds assessed by comparing characteristics of inhomogeneities found in real data to that found in the analogue-error worlds. This will help improve future benchmarks.

For level 1 assessment of large-scale features (i.e. $c, l$ and $v$ in Eq. 1), a perfect algorithm would return the analogue-clean world features. Algorithms should, ideally, at least make the analogue-error worlds more similar to their analogue-clean worlds. Climatology, variability and long-term trends can be calculated for stations, regional averages or global averages from each adjusted analogue-error world. Similarity can be measured in terms of proximity in degrees Celsius for the climatology and linear-trend approximations and standard deviation as a measure of variability. This can be presented as percentage recovery (after Williams et al., 2012). An example is shown in Fig. 2 for linear trend approximations with further explanation. Although linear trends do not describe the data perfectly, they provide a simple measure of long-term tendency that can be compared. This method does not indicate algorithms that result in a linear trend of the wrong sign (positive or negative). This may be seen as a more serious problem than a linear trend being over- or underestimated. Other scores, such as the squared error or the absolute error, could also be used to measure differences between adjusted analogue-error worlds and analogue-clean worlds.

Levels 2 and 3 are important for the developers of homogenisation methods. They can be split into accuracy of change-point location detection and the accuracy of inhomogeneity adjustments applied. In the case of gradual or seasonally varying inhomogeneities, the slope and seasonal cycle of

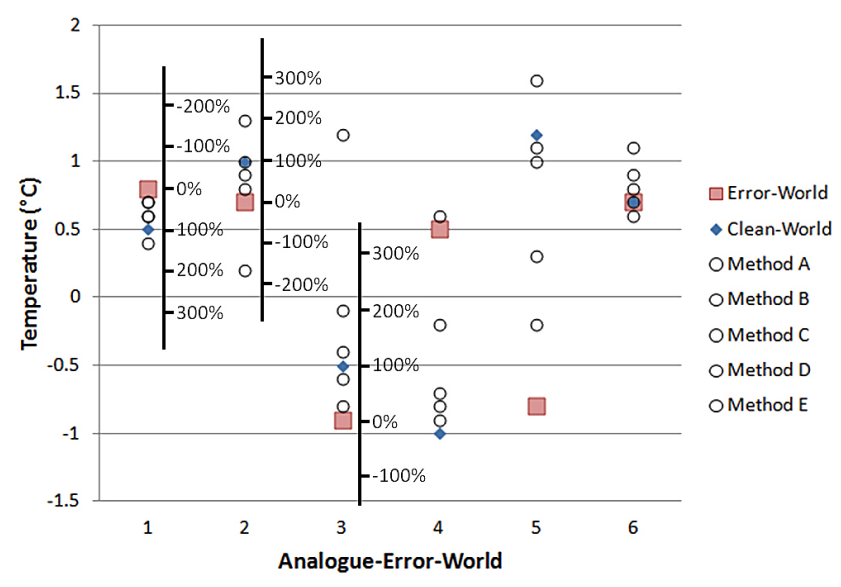

Figure 2. Example summary graph of algorithm skill for five hypothetical methods across six analogue-error worlds measured as trend-percentage recovery. This uses the trends calculated from an adjusted analogue-error world scaled against the difference between the analogue-error world and its corresponding analogueclean world. A $100 \%$ trend recovery would indicate a perfect algorithm. Greater than $100 \%$ would be moving the trend too far in the right direction. Less than $100 \%$ would be an algorithm that does not move the trend far enough towards the analogue-clean world. A negative percentage would indicate an algorithm that moves the trend in the wrong direction. This method does not indicate algorithms that result in a trend of the wrong sign (positive or negative). This may be seen as a more serious problem than a trend being overor underestimated and so would need to be identified separately.

the adjustments should also be assessed. Furthermore, a sliding scale may be used to penalise close but not exact hits rather than assigning them as misses. Care should be taken though considering that some algorithms may adjust the inhomogeneous data well, performing highly in the level 1 assessment, while not locating change points accurately or vice versa. For example, many small inhomogeneities may be homogenised by locating a single change point and applying a single large amplitude inhomogeneity adjustment or vice versa. Similarly, a gradual inhomogeneity may be homogenised by applying multiple small adjustments. Large inhomogeneities are easier to detect than small ones so assessment could be split into inhomogeneity size categories (e.g. Zhang et al., 2012). This information is of importance to algorithm developers.

Arguably, adjusting for detected inhomogeneities that are not actual inhomogeneities (false detection) adds error to the data and so could be scored more negatively than missing a real inhomogeneity. However, this critically depends upon the size of the adjustments applied. If adjustments for false detections are small there will be little change in climatology and trend statistics, hence the cost of false detection diminishes.

Such assessments of detection and adjustment skill could be done through contingency tables (Table 2) where numbers 
Table 2. Example contingency table for assessing change-point location detection and inhomogeneity adjustment skill (option shown in brackets) of homogenisation algorithms. Potential detections are the number of potential change points within the time period minus the total number of detections and misses. These are used to quantify those occasions where no change point is found and none is present. One way to do this is to assume that there is potentially a maximum of 1 change point every 6 months (some algorithms can only search for change points with 6 months of data on either side) such that a 26-year period will have 52 potential change points.

\begin{tabular}{|c|c|c|c|}
\hline & Change point & No. change points present & Totals \\
\hline $\begin{array}{l}\text { Change point detected } \\
\text { within } \pm 3 \text { months } \\
\text { (inhomogeneity adjustment } \\
\text { with the correct sign }( \pm \text { ) } \\
\text { and within } \pm 1^{\circ} \mathrm{C} \text { ) }\end{array}$ & $\begin{array}{l}\text { Hits: } \\
5(4)\end{array}$ & $\begin{array}{l}\text { False alarms: } \\
3(3)\end{array}$ & $8(7)$ \\
\hline $\begin{array}{l}\text { Change point not detected } \\
\text { within } \pm 3 \text { months } \\
\text { (inhomogeneity adjustment } \\
\text { value with the incorrect } \\
\text { sign or not within } \pm 1^{\circ} \mathrm{C} \text { ) }\end{array}$ & $\begin{array}{l}\text { Misses: } \\
2(3)\end{array}$ & $\begin{array}{l}\text { Correct non-detections: } \\
42(42) \\
\text { (potential detections) }\end{array}$ & $44(45)$ \\
\hline Totals & $7(7)$ & $45(45)$ & $52(52)$ \\
\hline $\begin{array}{l}\text { Heidke skill score } \\
\text { Probability of detection hit ro } \\
\text { False alarm rate }\end{array}$ & & $\begin{array}{c}61 \%(50 \%) \\
71 \%(57 \%) \\
7 \%(7 \%)\end{array}$ & \\
\hline
\end{tabular}

of hits, misses, false alarms and "correct non-detections" are counted and used to construct various skill scores (Menne and Williams, 2005). Defining the number of "correct nondetections" is not straightforward, especially where a sliding scale is used to define a "hit". A method for doing this needs to be investigated. Alternatively, measures that consider only hits, misses and false alarms may be used. The ideas used to assess detection skill can be adapted to investigate size-ofadjustment skill, as shown in red in Table 2 . This could be visualised for each data product using a scatter plot where each analogue-error world result is positioned according to its hit rate and false alarm rate. Users can quickly see on which worlds that particular data product/algorithm scores highly (high hit rate and low false alarm rate), and which worlds are problematic. This can be used to infer applicability of data products for a specific use or intercomparison with data products created from different algorithms.

Level 4 assessment should help inform us which analogueerror world is most similar to reality (if any) in terms of detected change points for each algorithm. This is useful for two reasons. Firstly, assuming the error structure is realistic, it may help to tell us something about uncertainty due to inhomogeneities remaining in the data. Secondly, it helps to improve later versions of benchmarks in terms of developing realistic error models.

Levels 1 and 2 are of primary focus for assessing uncertainty and comparing data products. Level 3 is of more importance to algorithm developers than data-product users, informing where best to focus future algorithm improvements. Level 4 is mainly aimed at the working group. For the first benchmark cycle, assessment should focus on levels 1 and 2 to provide a quick response to the benchmark users. Ultimately, all worlds and results from the assessment will be made publicly available, ideally alongside any associated data products. This will allow for further bespoke assessment as required by interested analysts.

It is important that this process is made easy to encourage participation. Ideally, all participants would submit a homogenised version of all stations in each analogue-error world. Additionally, a list should be provided of detected change points. Optionally, submission of information about the adjustments applied could also be encouraged (e.g. magnitude, slope/non-linear-trend function, and seasonal cycle). This would enable the assessment of all levels. However, it is more likely that different groups will select different stations based on their desired end product. These may be limited to long stations only or limited to specific regions. This could be problematic for contingency table assessment given the inherent tendency for false alarm rates/miss rates to grow with increasing numbers of test events (i.e. number of stations). Some groups may wrap their homogenisation into a fully gridded product such that they are unable to provide individual homogenised stations or a list of adjustments. This would prevent any level 2 and 3 assessment.

Given the above, while it is important to specify an ideal set of items to submit as part of the benchmarking assessment, it is also important to have the capacity to accept a wide variety of submissions. This may be done for level 1 by performing assessment both at the station scale and also at the regional-average scale, accepting that some component of differences found will be due to station selection and gridding methods. For stations and regional averages, 


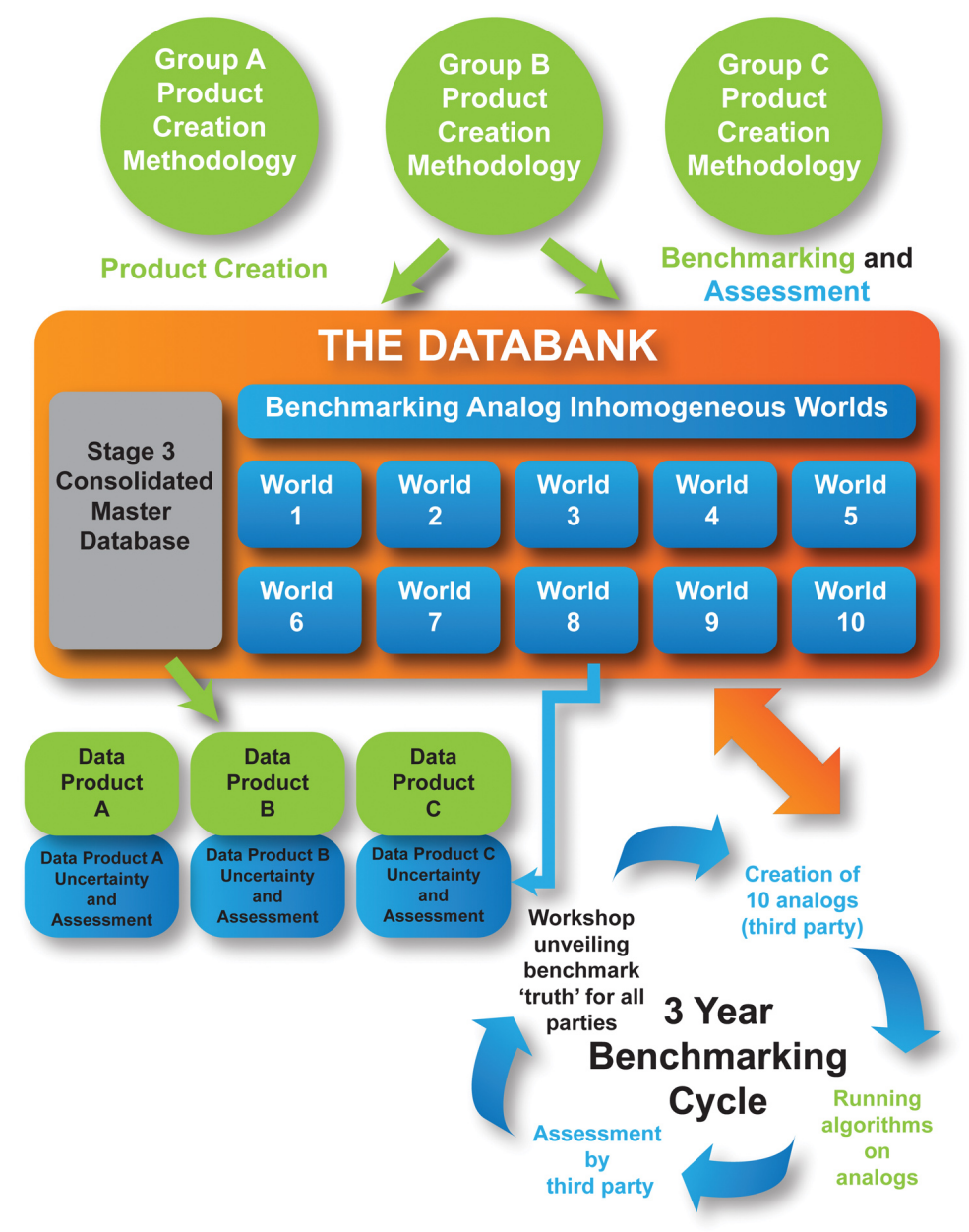

Figure 3. Schematic of the benchmarking assessment and benchmark cycle (source: Fig. 3 in Thorne et al., 2011).

participants could be asked to submit their best estimates of specified statistics such as the climatology, variance and linear trend. A set of regions could be specified such as the Giorgi regions commonly used within many aspects of climate science (Giorgi and Francisco, 2000) in addition to hemispheric and global averages. A more accurate comparison could be done if groups submit lists of the stations included in gridded/regional products. It would also be possible to specify a minimum subset of stations to be homogenised to allow for a fair comparison across the regionally focussed products, some of which may use manual homogenisation methods and therefore unable to tackle globalscale homogenisation (cf. Venema et al., 2012). An important distinction could be made between best estimates of cleanworld regional statistics and statistics calculated on all stations within that region. In some cases it would be a wise decision to remove a station that has too many missing data or that is too poor in quality; however comparisons using all stations in the analogue-clean world compared to a participant's best estimate may penalise such approaches.

\section{Providing a working cycle of benchmarking to serve the needs of science and policy}

To ensure that homogenisation benchmarking achieves its full potential in terms of usefulness, the benchmarks need to be easily accessible and the assessment process timely with results that are easy to use. We envisage making the benchmark worlds available alongside the ISTI databank in identical format (Fig. 3) such that data-product creators can easily process them in addition to the real data.

A repeatable cycle of blind benchmark release (analogueerror worlds), homogenisation period, assessment period, release of the underlying analogue-clean worlds/answers (change-point locations, size and shape of inhomogeneities added) and a wrap-up workshop would encourage people to use the benchmarks and allow for sequential improvement of the benchmarks and investigation of different homogenisation issues. Not all issues will be able to be covered in the first cycle. This could be a 3-year cycle, overseen by the Benchmarking and Assessment Working Group (Fig. 3). 
If the cycle is too short then there are risks that not enough people will get involved, reducing the usefulness of product intercomparison. If the cycle is too long then the benchmarks become out of date and the assessment is too slow to be used alongside the CDR. Additionally, much may be learned about each analogue-error world from homogenising even without release of the underlying analogue-clean world. This runs the risk of second or third versions of algorithms becoming overtuned to these specific worlds.

The wrap up would bring together users and creators of the benchmarks to assess how they were useful and how they can be improved for the next cycle. This will likely be in the form of a workshop and overview analysis paper. The databank will develop over time as will algorithms and the benchmarks will need to be updated both in terms of station coverage and methodologically.

The focus here is limited to monthly mean temperature data but it is envisaged that maximum and minimum temperatures and, subsequently, daily temperature records will be included in the future. Also, the current framework is only set up to assess the homogenisation algorithm skill. There are many different aspects of data-product creation including quality-control processes, station selection and interpolation and gridding methods. The benchmarks created here could also be used to assess some of these, but at this time it was thought advantageous to focus only on the homogenisation element in order to make faster progress. We hope that the provision of this benchmarking framework will broaden in the future to include these other important aspects of dataproduct creation.

\section{Concluding remarks}

An international and comprehensive benchmarking system for homogenisation of global surface temperature data is essential for constraining the uncertainty in climate data arising from changes made to our observing system. The International Surface Temperature Initiative is in a unique position to undertake this work and provide testing alongside the provision of the raw climate data. A repeating cycle of benchmarking assessment has been proposed including concepts for creation of benchmark data and their assessment. The task is large and will take time to accomplish. However, this will for the first time enable global-scale quantification of uncertainty in station inhomogeneity, which is one of the least understood areas of uncertainty associated with the land surface air temperature record.

The assessment of skill against the benchmarks will enable meaningful intercomparisons of surface temperature products and assessment of fitness for purpose for a broad range of end users from large-scale climate monitoring to localscale societal impacts analysis. Such a detailed and global testing of homogenisation algorithms will also be a significant aid to algorithm developers, hopefully resulting in vastly improved algorithms for the future. These benchmarks can also be used to test other aspects of climate data record production such as station selection and interpolation. If successful, this work should significantly improve the robustness of monthly surface temperature climate data records on a range of spatial scales. This will improve the accuracy of assessment of recent changes in surface temperature and associated uncertainties to end users.

Ultimately, the value of these benchmarks will only be as great as the number of groups participating in the exercise. The authors therefore strongly advocate development of new approaches and climate data records by new groups. The value of the new records will be greatly enhanced by undertaking benchmark testing as well as by using ISTI databank data.

\section{Copyright statement}

The works published in this journal are distributed under the Creative Commons Attribution 3.0 License. This license does not affect the Crown copyright work, which is re-usable under the Open Government Licence (OGL). The Creative Commons Attribution 3.0 License and the OGL are interoperable and do not conflict with, reduce or limit each other.

() Crown copyright 2014

Acknowledgements. The work of Kate Willett was supported by the Joint UK DECC/Defra Met Office Hadley Centre Climate Programme (GA01101). Renate Auchmann was funded by the Swiss National Science Foundation (project TWIST). Constructive and comprehensive reviews by Blair Trewin, Richard Cornes and an anonymous reviewer served to improve the manuscript and are gratefully acknowledged.

Edited by: L. Eppelbaum

\section{References}

Aguilar, E., Auer, I., Brunet, M., Peterson, T. C., and Wieringa, J.: Guidelines on climate metadata and homogenization, WCDMP 53, WMO-TD 1186, World Meteorol. Organ., Geneva, Switzerland, 55 pp., 2003.

Auchmann, R. and Brönnimann, S.: A physics-based correction model for homogenizing sub-daily temperature series, J. Geophys. Res., 117, D17119, doi:10.1029/2012JD018067, 2012.

Begert, M., Zenklusen, E., Häberli, C., Appenzeller, C., and Klok, I.: An automated procedure to detect changepoints; performance assessment and application to a large European climate data set, Meteorol. Z., 17, 663-672, 2008.

Böhm, R., Auer, I., Brunetti, M., Maugeri, M., Nanni, T., and Schöner, W.: Regional temperature variability in the European Alps 1760-1998 from homogenized instrumental time series, Int. J. Climatol., 21, 1779-1801, 2001. 
Brockwell, P. J. and Davis, R. A.: Time Series: Theory and Methods, 2nd Edn., Springer, New York, NY, 2006.

Brunet, M., Saladié, O., Jones, P. D., Sigró, J., Aguilar, E., Moberg, A., Lister, D., Walther, A., Lopez, D., and Almarza, C.: The development of a new dataset of Spanish daily adjusted temperature series (1850-2003), Int. J. Climatol., 26, 1777-1802, doi:10.1002/joc.1338, 2006.

Caussinus, H. and Lyazrhi, F.: Choosing a linear model with a random number of change-points and outliers, Ann. Inst. Statist. Math., 49, 761-775, 1997.

Caussinus, H. and Mestre, O.: Detection and correction of artificial shifts in climate series, J. Roy. Stat. Soc. Ser. C, 53, 405-425, 2004.

DeGaetano, A. T.: Attributes of several methods for detecting changepoints in mean temperature series, J. Climate, 19, 838853,2006

Domonkos, P., Poza, R., and Efthymiadis, D.: Newest developments of ACMANT, Adv. Sci. Res., 6, 7-11, doi:10.5194/asr-6-7-2011, 2011.

Ducré-Robitaille, J.-F., Vincent, L. A., and Boulet, G.: Comparison of techniques for detection of changepoints in temperature series, Int. J. Climatol., 23, 1087-1101, 2003.

Easterling, D. R. and Peterson, T. C.: The effect of artificial changepoints on recent trends in minimum and maximum temperatures, International Minimax Workshop on Asymmetric Change of Daily Temperature Range, College Parg, MD, September 2730, 1993, Atmos. Res., 37, 19-26, 1995.

Giorgi, F. and Francisco, R.: Evaluating uncertainties in the prediction of regional climate change, Geophys. Res. Lett., 27, 12951298, 2000.

Hannart, A. and Naveau, P.: An improved Bayes Information Criterion for multiple change-point models, Technometrics, 54, 256268, doi:10.1080/00401706.2012.694780, 2012.

Harrison, R. G.: Natural ventilation effects on temperatures within Stevenson screens, Q. J. Roy. Meteorol. Soc., 136, 253-259, doi:10.1002/qj.537, 2010.

Harrison, R. G.: Lag-time effects on a naturally ventilated large thermometer screen, Q. J. Roy. Meteorol. Soc., 137, 402-408, doi:10.1002/qj.745, 2011.

Karl, T. R., Williams Jr., C. N., Young, P. J., and Wendland, W. M.: A model to estimate the time of observation bias associated with monthly mean maximum, minimum, and mean temperature for the United States, J. Clim. Appl. Meteorol., 25, 145-160, 1986.

Lawrimore, J. H., Menne, M. J., Gleason, B. E., Williams, C. N., Wuertz, D. B., Vose, R. S., and Rennie, J.: An overview of the Global Historical Climatology Network Monthly Mean Temperature Dataset, Version 3, J. Geophys. Res.-Atmos., 116, D19121, doi:10.1029/2011JD016187, 2011.

Lindau, R. and Venema, V. K. C.: On the multiple breakpoint problem and the number of significant breaks in homogenisation of climate records. Idojaras, Q. J. Hung. Meteorol. Serv., 117, 134, 2013.

Lu, Q., Lund, R. B., and Lee, T. C. M.: An MDL approach to the climate segmentation problem, Ann. Appl. Stat., 4, 299-319, doi:10.1214/09-AOAS289, 2010.

Menne, M. J. and Williams, C. N.: Detection of undocumented changepoints using multiple test statistics and composite reference series, J. Climate, 18, 4271-4286, 2005.
Menne, M. J. and Williams Jr., C. N.: Homogenization of temperature series via pairwise comparisons, J. Climate, 22, 1700-1717, 2009.

Menne, M. J., Williams Jr., C. N., and Vose, R. S.: The United States Historical Climatology Network monthly temperature data-Version 2, B. Am. Meteorol. Soc., 90, 993-1007, 2009.

Parker, D. E.: Effects of changing exposure of thermometers at land stations, Int. J. Climatol., 14, 1-31, 1994.

Peterson, T. C., Easterling, D. R., Karl, T. R., Groisman, P., Nicholls, N., Plummer, N., Torok, S. Auer, I., Boehm, R., Gullett, D., Vnicent, L., Heino, R., Tuomenvirta, H., Mestre, O., Szentimrey, T., Salinger, S., Førland, E., Hanssen-Bauer, I., Hans Alexandersson, Jones, P., and Parker, D. E.: Homogeneity adjustments of in situ atmospheric climate data: A review, Int. J. Climatol., 18, 1493-1517, 1998.

Quayle, R. G., Easterling, D. R., Karl, T. R., and Hughes, P. Y.: Effects of Recent Thermometer Changes in the Cooperative Station Network, B. Am. Meteorol. Soc., 72, 1718-1723, 1991.

Reeves, J., Chen, J., Wang, Z. L., Lund, R., and Lu, Q.: A Review and Comparison of Changepoint Detection Techniques for Climate Data. J. Appl. Meteor. Climatol., 46, 900-915, doi:10.1175/JAM2493.1, 2007.

Rennie, J. J., Lawrimore, J. H., Gleason, B. E., Thorne, P. W., Morice, C. P., Menne, M. J., Williams, C. N., de Almeida, W. G., Christy, J. R., Flannery, M., Ishihara, M., Kamiguchi, K., Klein-Tank, A. M. G., Mhanda, A., Lister, D. H., Razuvaev, V., Renom, M., Rusticucci, M., Tandy, J., Worley, S. J., Venema, V., Angel, W., Brunet, M., Dattore, B., Diamond, H., Lazzara, M. A., Le Blancq, F., Luterbacher, J., Mächel, H., Revadekar, J., Vose, R. S., and Yin, X.: The international surface temperature initiative global land surface databank: monthly temperature data release description and methods, Geoscience Data Journal, doi:10.1002/gdj3.8, online first, 2014.

Rohde, R., Muller, R. A., Jacobsen, R., Muller, E., Perlmutter, S., Rosenfeld, A., Wurtele, J., Groom, D., and Wickham, C.: A New Estimate of the Average Earth Surface Land Temperature Spanning 1753 to 2011, Geoinfor Geostat: An Overview, 1, 7 pp., doi:10.4172/2327-4581.1000101, 2013.

Seneviratne, S. I., Nicholls, N., Easterling, D., Goodess, C. M., Kanae, S., Kossin, J., Luo, Y., Marengo, J., McInnes, K., Rahimi, M., Reichstein, M., Sorteberg, A., Vera, C., and Zhang, X.: Changes in climate extremes and their impacts on the natural physical environment, in: Managing the Risks of Extreme Events and Disasters to Advance Climate Change Adaptation, edited by: Field, C. B., Barros, V., Stocker, T. F., Qin, D., Dokken, D. J., Ebi, K. L., Mastrandrea, M. D., Mach, K. J., Plattner, G.-K., Allen, S. K., Tignor, M. and Midgley, P. M., A Special Report of Working Groups I and II of the Intergovernmental Panel on Climate Change - IPCC, Cambridge University Press, Cambridge, UK, and New York, NY, USA, 109-230, 2012.

Thorne, P. W., Willett, K. M., Allan, R. J., Bojinski, S., Christy, J. R., Fox, N., Gilbert, S., Jolliffe, I., Kennedy, J. J., Kent, E., Klein Tank, A., Lawrimore, J., Parker, D. E., Rayner, N., Simmons, A., Song, L., Stott, P. A., and Trewin, B.: Guiding the Creation of a Comprehensive Surface Temperature Resource for 21st Century Climate Science, B. Am. Meteorol. Soc., 92, ES40-ES47, doi:10.1175/2011BAMS3124.1, 2011. 
Titchner, H. A., Thorne, P. W., McCarthy, M. P., Tett, S. F. B., Haimberger, L., and Parker, D. E.: Critically Reassessing Tropospheric Temperature Trends from Radiosondes Using Realistic Validation Experiments, J. Climate, 22, 465-485, doi:10.1175/2008JCLI2419.1, 2009.

Trewin, B.: Exposure, instrumentation, and observing practice effects on land temperature measurements, WIREs Clim. Change, 1, 490-505, 2010.

Trewin, B.: A daily homogenized temperature data set for Australia, Int. J. Climatol., 33, 1510-1529, doi:10.1002/joc.3530, 2013.

Venema, V., Bachner, S., Rust, H. W., and Simmer, C.: Statistical characteristics of surrogate data based on geophysical measurements, Nonlin. Processes Geophys., 13, 449-466, doi:10.5194/npg-13-449-2006, 2006.

Venema, V. K. C., Mestre, O., Aguilar, E., Auer, I., Guijarro, J. A., Domonkos, P., Vertacnik, G., Szentimrey, T., Stepanek, P., Zahradnicek, P., Viarre, J., Müller-Westermeier, G., Lakatos, M., Williams, C. N., Menne, M. J., Lindau, R., Rasol, D., Rustemeier, E., Kolokythas, K., Marinova, T., Andresen, L., Acquaotta, F., Fratianni, S., Cheval, S., Klancar, M., Brunetti, M., Gruber, C., Prohom Duran, M., Likso, T., Esteban, P., and Brandsma, T.: Benchmarking homogenization algorithms for monthly data, Clim. Past, 8, 89-115, doi:10.5194/cp-8-89-2012, 2012.

Vincent, L. A.: A technique for the identification of inhomogeneities in Canadian temperature series, J. Climate, 11, 10941104, 1998.

Vincent, L. A., Wang, X. L., Milewska, E. J., Wan, H., Yang, F., and Swail, V.: A second generation of homogenized Canadian monthly surface air temperature for climate trend analysis, J. Geophys. Res., 117, D18110, doi:10.1029/2012JD017859, 2012.
Wang, X. L.: Accounting for autocorrelation in detecting meanshifts in climate data series using the penalized maximal $t$ or $F$ test, J. Appl. Meteorol. Clim., 47, 2423-2444, doi:10.1175/2008JAMC1741.1, 2008a.

Wang, X. L.: Penalized maximal $F$ test for detecting undocumented mean-shift without trend change, J. Atmos. Ocean. Tech., 25, 368-384, doi:10.1175/2007JTECHA982.1, 2008b.

Wang, X. L., Wen, Q. H., and Wu, Y.: Penalized Maximal $t$ Test for Detecting Undocumented Mean Change in Climate Data Series, J. Appl. Meteorol. Clim., 46, 916-931, doi:10.1175/JAM2504.1, 2007.

Williams Jr., C. N., Menne, M. J., and Thorne, P.: Benchmarking the performance of pairwise homogenization of surface temperatures in the United States, J. Geophys. Res., 117, D05116, doi:10.1029/2011JD016761, 2012.

WMO: WMO No. 182, International meteorological vocabulary, Geneva, Switzerland, 1992.

WMO: Final Report, Commission for Basic Systems. Working Group on Data Processing, Task Group on WMO/CTBTO Matters, 15-17 July 1998, www.wmo.int/pages/prog/www/reports/ wmo-ctbto.html, Geneva, Switzerland, 1998.

Xu, W., Li, Q., Wang, X. L., Yang, S., Cao, L., and Feng, Y.: Homogenization of Chinese daily surface air temperatures and analysis of trends in the extreme temperature indices, J. Geophys. Res.-Atmos., 118, 9708-9720, doi:10.1002/jgrd.50791, 2013.

Zhang, J., Zheng, W., and Menne, M. J.: A Bayes factor model for detecting artificial discontinuities via pairwise comparisons, J. Climate, 25, 8462-8474, doi:10.1175/JCLI-D-12-00052.1, 2012. 